\title{
The Risk of Venous Thromboembolism in Algerian Patients
}

Chalal $\mathbf{N}$ and Demmouche $A^{*}$

Department of Biology, Faculty of Science, DjillaliLiabes University, SidiBel Abbes, Algeria

\begin{abstract}
Venous thromboembolism (VTE) including deep venous thrombosis and pulmonary embolism is a common disease associated with substantial morbidity and mortality. VTE is becoming increasingly common in Algeria but published data on its frequency and risk factors are lacking.

The purpose of our study was to determine the frequency, risk factors of this disease in Sidibel abbes region, Northwest Algeria.

A retrospective study of patients hospitalized for DVT and/or PE was carried out between January 1, 2006 and June 10, 2012 at the cardiology department of Sidibel abbes University Hospital Center.

183 VTE patients (71 men [38.7\%, age $51.5 \pm 17.7$ years] and 112 women [61.2\%, age $46.4 \pm 17.9$ years]) were included. Deep venous thrombosis (DVT) occurred in $146(79.7 \%)$, pulmonary embolism (PE) in $37(20.2 \%)$ including 16 with concurrent DVT.

The most common risk factors among DVT patients were: immobility, hypertension, surgery and oral contraception whereas, immobility, surgery, hypertension and fractures were the most frequent risk factors among PE patients.

$12.02 \%$ of patients had a previous VTE. $24.7 \%$ of patients had several risk factors. Lower extremity DVT accounted for $97.5 \%$ of cases and upper extremity DVT for only $2.5 \%$.

In conclusion, although its frequency is not a cause for alarm, it will be important to adopt a suitable prophylactic strategy to combat the growing prevalence of VTE in the region of SidiBel Abbes.
\end{abstract}

Keywords: Venous thromboembolism; Frequency; Risk factors; Sidibel abbes

\section{Introduction}

Venous thromboembolism (VTE) is a disease that comprises two clinical entities: deep vein thrombosis and pulmonary embolism. This common disease with an annual incidence of 1-2 per 1000 in the general population can be fatal or result in serious functional disability $[1,2]$. The impact of VTE on morbidity and mortality together with the health care costs it engenders make this disease a major public health problem.

While rare in childhood - with a negligible yearly incidence of less than 5 per 100.000-the incidence of VTE rises sharply with age, reaching $450-600$ per 100.000 per year, and is primarily a disease of the elderly [3].

The risk of thrombosis is probably potentiated by a synergistic combination of factors in the renowned triad described by Virchow in 1884: venous stasis, endothelial injury and hypercoagulability. The pathogenesis of VTE results from a complex interplay of genetic and environmental factors, both transient and acquired [4].

An ever more detailed set of decision rules for assessing thrombotic risk is the key to optimizing prophylactic intervention aimed at significantly lowering morbidity and mortality of venous thromboembolic disease.

In Algeria, the prevalence of this disease is on the rise but there are no published data on its frequency or on the thrombogenic potential of associated risk factors.

This retrospective study helps to shed some light on the true situation of venous thromboembolism in the SidiBel Abbes region (Northwest Algeria).

\section{Patients and Methods}

This was a retrospective study of patients hospitalized for DVT and/ or PE in the cardiology department of the SidiBel Abbes University Hospital Center between January $1^{\text {st }} 2006$ and June $10^{\text {th }} 2012$.

The diagnosis of VTE was confirmed by Doppler ultrasonography or computed tomographic pulmonary angiography.

Data on age, risk factors and site of this disease were retrieved from medical records. Results are expressed as: Mean \pm SD or $n(\%)$. Statistical analyses and calculations were performed using Stat view (version 5.0 for Windows; SAS Institute).

\begin{tabular}{|c|l|l|l|}
\hline Variables & $\begin{array}{l}\text { All VTE patients } \\
(\mathbf{n = 1 8 3 )}\end{array}$ & $\begin{array}{l}\text { Men } \\
(\mathbf{n = 7 1 )}\end{array}$ & $\begin{array}{l}\text { Women } \\
(\mathbf{n}=\mathbf{1 1 2})\end{array}$ \\
\hline Age (years) & $48.4 \pm 17.9$ & $51.5 \pm 17.7$ & $46.4 \pm 17.9$ \\
\hline DVT & $146(79.7)$ & $52(73.2)$ & $94(83.9)$ \\
\hline PE & $37(20.2)$ & $19(26.7)$ & $18(16)$ \\
\hline
\end{tabular}

DVT=Deep vein thrombosis; $P E=$ Pulmonary embolism

Table 1: Characteristics of patients with venous thromboembolism (VTE), Mean $\pm \mathrm{SD}$ or $\mathrm{n}(\%)$.

*Corresponding author: Demmouche Abbassia, Doctor in Biology at DjillaliLiabes University, Algeria, Tel: 213 773620637; E-mail: demmoucheabbassia@yahoo.fr

Received February 25, 2014; Accepted March 24, 2014; Published March 27 2014

Citation: Chalal N, Demmouche A (2014) The Risk of Venous Thromboembolism in Algerian Patients. Pharm Anal Acta 5: 292. doi: 10.4172/2153-2435.1000292

Copyright: @ 2014 Chalal N, et al. This is an open-access article distributed under the terms of the Creative Commons Attribution License, which permits unrestricted use, distribution, and reproduction in any medium, provided the original author and source are credited. 


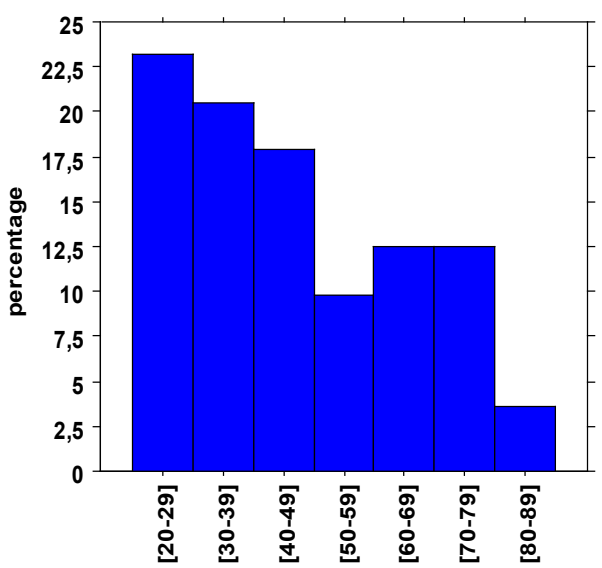

Age (years)

Female( $n=112)$

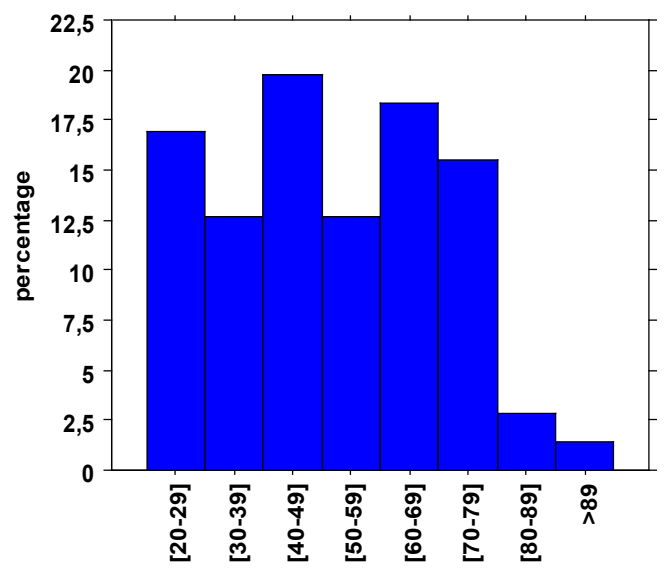

Age ( years)

male $(n=71)$

Figure 1: Age distribution in female $(n=112)$ and male $(n=71)$ patients with venous thromboembolism.

\section{Results}

During the study period, 183 patients were hospitalized with VTE, including 112 women (61.2\%) with a mean age $46.4 \pm 17.9$ years and 71 men $(38.7 \%)$ with a mean age of $51.5 \pm 17.7$ years (Table 1 ).

The proportion of women aged 20-39 years was higher than that aged 40-89, suggesting that women are more exposed to this type of pathology during their childbearing years, while in men, on the other hand, it is generally more common after age 40 (Figure 1).

There were 146 cases $(79.7 \%)$ of isolated DVT and 37 cases $(20.2 \%)$ of PE including 16 with concurrent DVT.

Among DVT patients, risk factors with a high thrombogenic potential were mainly immobility, hypertension, surgery and oral contraception. For PE patients, major risk factors were immobility, surgery, hypertension and fractures (Table 2). A previous VTE event was present in $12.02 \%$ of patients. $24.7 \%$ of patients had more than two risk factors, $43.5 \%$ had two and $31.6 \%$ had a single risk factor (Figure 2), whereas for 16 patients (8.7\%: $14 \mathrm{DVT}$ and $2 \mathrm{PE}$ ), no risk factors were identified.

Among 158 patients with lower limb DVT, the location was proximal in $97.5 \%$ and distal in $2.5 \%$, and the majority affected the left leg (101 cases) versus 47 cases in the right leg and 10 with a bilateral location (Table 3).

In contrast, only 4 cases of upper limb DVT were observed, mainly on the left (Table 3), including a woman with breast cancer and one with malignant melanoma, and two men with no apparent underlying cause.

Analysis of administered treatment showed that (98\%) of DVT patients received $\mathrm{LMH},(96 \%) \mathrm{OAC},(2.7 \%) \mathrm{UFH}$ whereas, Of PE patients, (97\%) received LMH, (95\%) OAC, (16.2\%) UFH and (13.5\%) thrombolysis. $34,4 \%$ of patients received no prophylaxis.

Mortality rate is estimated at $3,82 \%$ of patients including 5 patients with isolated PE and 2 patients with both PE and DVT.

\section{Discussion}

The incidence of venous thromboembolic events increases with

\begin{tabular}{|l|c|c|}
\hline & $\begin{array}{c}\text { DVT patients } \\
\mathbf{n = 1 4 6}\end{array}$ & $\begin{array}{c}\text { PE patients } \\
\mathbf{n = 3 7}\end{array}$ \\
\hline Age (years) & $48 \pm 18.1$ & $50 \pm 17.7$ \\
\hline Smoking & $11(7.5)$ & $3(8.1)$ \\
\hline Obesity & $4(2.7)$ & $5(13.5)$ \\
\hline Immobility & $39(26.7)$ & $14(37.8)$ \\
\hline Surgery & $18(12.3)$ & $10(27)$ \\
\hline Fractures & $11(7.5)$ & $8(21.6)$ \\
\hline Pregnancy & $4(2.7)$ & $0(0)$ \\
\hline Postpartum & $15(10.2)$ & $5(13.5)$ \\
\hline Post abortum & $2(1.3)$ & $0(0)$ \\
\hline Oral contraceptives & $16(10.9)$ & $2(5.4)$ \\
\hline Cancer & $10(6.8)$ & $4(10.8)$ \\
\hline Diabetes & $9(6.1)$ & $2(5.4)$ \\
\hline Hypertension & $21(14.3)$ & $9(24.3)$ \\
\hline Behçet's disease & $4(2.7)$ & $0(0)$ \\
\hline Nephrotic syndrome & $9(6.1)$ & $0(0)$ \\
\hline Heart failure & $8(5.4)$ & $0(0)$ \\
\hline Stroke & $2(1.3)$ & $2(5.4)$ \\
\hline Myocardial infarction & $1(0.6)$ & $3(8.1)$ \\
\hline Varicose veins & $7(4.7)$ & $1(2.7)$ \\
\hline Pulmonary tuberculosis & $6(4.1)$ & $0(0)$ \\
\hline Previous VTE & $15(10.2)$ & $7(18.9)$ \\
\hline No obvious risk factor & $14(9.5)$ & $2(5.4)$ \\
\hline DVT-Dep Vein Thrombosis & & \\
\hline
\end{tabular}

DVT=Deep Vein Thrombosis; PE=Pulmonary Embolism

Table 2: Risk factors in 183 patients with deep venous thrombosis (DVT) or pulmonary embolism (PE), mean \pm SD or $n(\%)$.

age, which is an independent thromboembolic risk factor. This risk is all the higher because age is also associated with a higher frequency of comorbidities such as surgery, immobility or cancer, which promote the development of venous thrombosis [5].

The incidence of first-time VTE rises exponentially with age, from a negligible rate ( $<5$ per 100.000 per year) among children $<15$ years of age to values in the range of 450 to 600 per 100.000 per year $(\approx 0.5 \% /$ year $)$ among individuals over the age of 80 years 3. According to Oger et al. [6], the incidence of VTE increases sharply with age, reaching $1 \%$ in individuals over 75 , which is twice as high than in patients aged 60-74 [6]. 


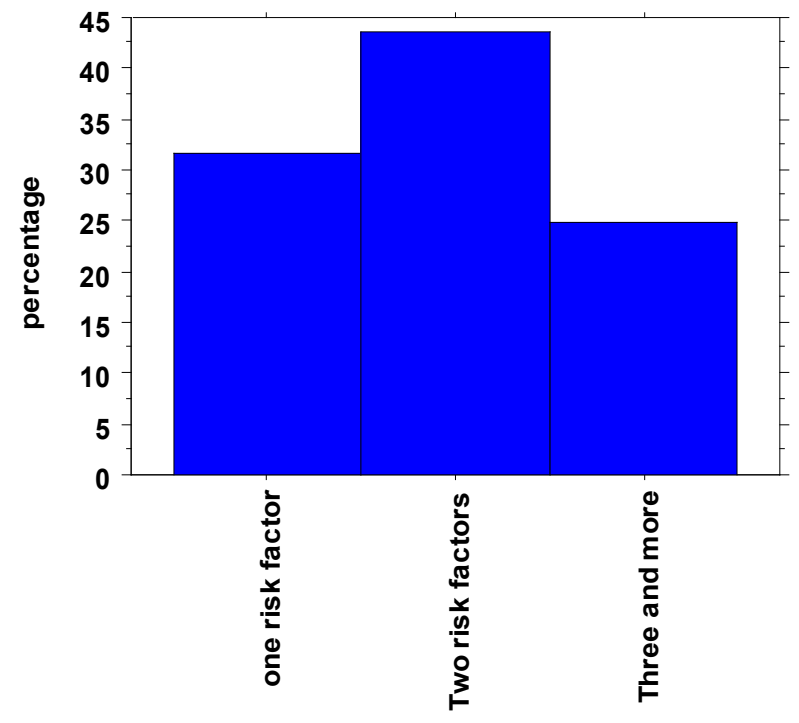

Number of risk factors

Figure 2: Distribution of cases according to the number of risk factors.

\begin{tabular}{|l|l|l|l|}
\hline $\begin{array}{l}\text { Lower extremity DVT } \\
(\mathbf{n = 1 5 8})\end{array}$ & $\begin{array}{l}\text { Left DVT } \\
(\mathbf{n = 1 0 1 )}\end{array}$ & $\begin{array}{l}\text { Right DVT } \\
\mathbf{( n = 4 7 )}\end{array}$ & $\begin{array}{l}\text { Bilateral DVT } \\
\mathbf{( n = 1 0 )}\end{array}$ \\
\hline lliofemoral+IVC DVT & $0(0)$ & $3(6.3)$ & $0(0)$ \\
\hline lliofemoral DVT & $17(16.8)$ & $5(10.6)$ & $2(20)$ \\
\hline lliofemoro-popliteal DVT & $34(33.6)$ & $10(21.2)$ & $3(30)$ \\
\hline Femoropopliteal DVT & $37(36.6)$ & $18(38.2)$ & $5(50)$ \\
\hline Femoral DVT & $2(1.9)$ & $8(17)$ & $0(0)$ \\
\hline Popliteal DVT & $8(7.9)$ & $2(4.2)$ & $0(0)$ \\
\hline Tibial DVT & $3(2.9)$ & $1(2.1)$ & $0(0)$ \\
\hline $\begin{array}{l}\text { Upper extremity DVT } \\
\text { (n=4) }\end{array}$ & $\begin{array}{l}\text { Left DVT } \\
(\mathbf{n = 3})\end{array}$ & $\begin{array}{l}\text { Right DVT } \\
(\mathbf{n = 1})\end{array}$ & $\begin{array}{l}\text { Bilateral DVT } \\
(\mathbf{n}=\mathbf{0})\end{array}$ \\
\hline $\begin{array}{l}\text { Axillo-subclavian brachial } \\
\text { DVT }\end{array}$ & $3(100)$ & $0(0)$ & $0(0)$ \\
\hline Axillo-subclavian DVT & $0(0)$ & $1(100)$ & $0(0)$ \\
\hline
\end{tabular}

*Results are expressed as n (\%), IVC: Inferior Vena Cava

Table 3: Distribution of cases according to the location of DVT.

Women of childbearing age are more frequently affected than men of the same age, a difference which is attributable to pregnancy and to the use of oral contraceptives. On the other hand, among the elderly, women are at considerably lower risk than men [7].

The physiological changes that occur in the elderly, together with concomitant risk factors, provide a favorable environment for the development of VTE. The significant reduction in the diameter and resting blood flow velocity of the femoral vein that occurs in people over the age of 60 is a predisposing factor for DVT resulting from stagnant blood flow in this vein [7]. Prolonged bed rest and immobility promote venous dilatation and blood stasis [7].

A reduction in venous return resulting from an age-related decrease in the venous pump function of the calf muscles was found in a plethysmographic study in subjects aged 23-40 years and 60-83 years. In addition, an increase in the levels of coagulation factors VIII, V, VII and IX and a variation in prothrombotic markers were found to be correlated with age [7]. In our study, some thrombogenic factors were more frequent than others: immobility, hypertension, surgery and oral contraception were the main risk factors found in DVT patients while immobility, surgery, hypertension and fractures were found for PE.

Based on pathophysiological arguments, immobilization has been suspected of being a risk factor for venous thromboembolism (VTE). The supine position can lead to a muscular and diaphragm dysfunction which decreases the venous flow in the legs and causes "venous stasis" [8].

Venous stasis may in turn induce an hypercoagulability state, by activating the extrinsic pathway of coagulation via hypoxemia, and also by producing endothelial damage or by reducing the fibrinolytic activity [8].

Several studies have demonstrated that immobilization is a risk factor for VTE, as found in 17\% of patients with DVT and 18\% with PE in the study by Isma et al. and in 35\% of patients with PE according to Ouldzein et al. $[9,10]$.

Healy et al. [11] reported that prolonged work-related seated immobility was associated with a 2.8 -fold increase in the risk of VTE [11]. Fletcher et al. [12] found an association between VTE and immobilization for $36.3 \%$ of the women in the study cohort [12].

A positive association between blood pressure and VTE was found only in the study by Tsai et al. which classified hypertension as $>140 / 90$ $\mathrm{mm} \mathrm{Hg}$. The other studies used higher cutoff values $(>160 / 90 \mathrm{~mm} \mathrm{Hg})$ and found no effect [13].

Goldhaber et al. [14] identified hypertension as an independent predictor of PE in women [14].

Surgery increases the risk of VTE up to 20-fold, according to the type and duration of the procedure, the underlying pathology and the patient's condition, which can exacerbate venous stasis, a major component of thrombus formation $[15,16]$

Without routine prophylaxis, DVT rates in general surgery range from 10-40\% [17]. Abdominal, pelvic, orthopedic, neurosurgical, and oncologic surgeries place patients at the highest risk because of immobilization, secondary venous stenosis, and endothelial damage [18].

In addition to immobilization, stasis, and endothelial damage promoting DVT, surgery has been associated with activated coagulation and transient depression of fibrinolysis. An increase in thrombin activation as well as elevated levels of plasminogen activator inhibitor-1 (PAI-1) during the perioperative period have been described [18].

Women of childbearing age should always be asked if they are taking estrogen-progestin oral contraceptives, since combination birth control pills have long been associated with an increased risk of venous thromboembolism, which globally is multiplied by $4[19,20]$. The risk varies with different types of pills and with the dose. Thus, the risk is higher with increasing daily doses and with third generation versus second generation contraceptives [21-25].

The risk related to hormonal contraception is significantly modulated with age, especially beyond age 40 , but also in the presence of other risk factors [20].

Hemostatic anomalies such as low levels of protein $\mathrm{S}$ and antithrombin and acquired activated protein $C$ resistance have been observed in women taking oral contraceptives and provide a favorable biological environment for venous thrombosis [26-31].

Furthermore, the higher levels of SHBG (sex hormone binding 
globulin) with third generation versus second generation progestogens are considered to be a marker of thrombotic risk [32-36].

Thromboembolic events are common after trauma, particularly in case of fractures, and the risk is increased by a factor of 13 after a recent trauma [37].

With respect to upper extremity DVT, the thrombotic risk is multiplied by four in the presence of malignant disease and is six times higher following chemotherapy. The MEGA study found that this risk is 18 times higher than in patients without cancer [37].

A Dutch study showed that in cancer patients without an indwelling catheter, the presence of distant metastases increased the risk of upper extremity DVT (OR=11;95\%CI: 2-80) as compared with non-metastatic tumors. The types of malignancies most commonly associated with upper extremity DVT in the absence of a catheter were lung cancer, breast cancer and lymphomas [38]. A state of hypercoagulability induced by direct activation of factors involved in clotting and fibrinolysis and cells that play a role in clotting promote a higher risk of thrombosis [39].

In a review of 1231 consecutive patients treated for VTE, 96\% had at least one recognized risk factor. Furthermore, there is convincing evidence that the risk of VTE increases in proportion to the number of predisposing factors [40].

The risk of venous thromboembolism is considerably higher in patients who have had a previous VTE episode and the cumulative risk of recurrence after a previous episode is very high, which justifies considering VTE as a chronic disease. This risk is estimated at $5-10 \%$ per year [41-43]. Hansson found a 1-year recurrence rate of $7 \%$ and a 5 -year cumulative incidence of $21.1 \%$ after a first DVT and $27.9 \%$ after a second DVT. The risk of recurrence was higher for proximal thromboses [44].

\section{Conclusion}

The findings from our study show that despite a frequency which is not cause for alarm, we must nonetheless adopt rigorous measures to deal with the growing prevalence of VTE in the region of SidiBel Abbes.

VTE is an insidious and terrible disease with high morbidity and mortality. This is why it is essential to institute strict prophylactic measures adapted to the level of thrombotic risk. This risk stratification takes into account not only the type of surgery or medical pathology, but also the risk factors specific to the patient.

In addition to physical methods and simple rules of venous hygiene, such as early mobilization, passive and active mobilization, elevation of the legs, degressive compression stockings and breathing exercises, which must be implemented at all risk levels to prevent blood stasis and accelerate venous return, antithrombotic treatments are prescribed in patients at moderate or high risk.

Furthermore, in the context of preventive medicine, lifestyle and dietary measures are a top priority to reinforce therapeutic intervention in the management of metabolic syndrome.

\section{References}

1. Nordström M, Lindblad B, Bergqvist D, Kjellström T (1992) A prospective study of the incidence of deep-vein thrombosis within a defined urban population. $J$ Intern Med 232: 155-160.

2. Anderson FA Jr, Wheeler HB, Goldberg RJ, Hosmer DW, Patwardhan NA, et al. (1991) A population-based perspective of the hospital incidence and casefatality rates of deep vein thrombosis and pulmonary embolism. The Worcester DVT Study. Arch Intern Med 151: 933-938.

3. Silverstein MD, Heit JA, Mohr DN, Petterson TM, O'Fallon WM, et al. (1998) Trends in the incidence of deep vein thrombosis and pulmonary embolism: a 25-year population-based study. Arch Intern Med 158: 585-593.

4. Rosendaal FR (1999) Venous thrombosis: a multicausal disease. Lancet 353 1167-1173.

5. Mahé I, Caulin C, Bergmann JF (2005) Age, an independent risk factor for thrombosis. Epidemiologic data. Presse Med 34: 878-886.

6. Oger E (2000) Incidence of venous thromboembolism: a community-based study in Western France. EPI-GETBP Study Group. Grouped'Etude de la Thrombose de Bretagne Occidentale. Thromb Haemost 83: 657-660.

7. Mahé I, Caulin C, Bergmann JE (2005) What explains the increased rate of thromboses among the elderly? Pathophysiological data. Presse Med 34: 887895.

8. Pottier P, Hardouin JB, Lejeune S, Jolliet P, Gillet B, et al. (2009) Immobilization and the risk of venous thromboembolism. A meta-analysis on epidemiological studies. Thromb Res 124: 468-476.

9. Isma N, Svensson PJ, Gottsäter A, Lindblad B (2009) Prospective analysis of risk factors and distribution of venous thromboembolism in the populationbased Malmö Thrombophilia Study (MATS). Thromb Res 124: 663-666.

10. Ouldzein H, Nourredine A, Cherradi R, Rahal N, Mechmeche R, et al. (2008) Management of pulmonary embolism in a cardiology department. Ann Cardiol Angeiol (Paris) 57: 52-57.

11. Healy B, Levin E, Perrin K, Weatherall M, Beasley R (2010) Prolonged workand computer-related seated immobility and risk of venous thromboembolism. J R Soc Med 103: 447-454

12. Fletcher HM, Wharfe G, Williams NP, Pedican M, Brooks A, et al. (2009) Venous thromboembolism in Jamaican women: experience in a university hospital in Kingston. West Indian Med J 58: 243-249.

13. Tsai AW, Cushman M, Rosamond WD, Heckbert SR, Polak JF, et al. (2002) Cardiovascular risk factors and venous thromboembolism incidence: the longitudinal investigation of thromboembolism etiology. Arch Intern Med 162 1182-1189.

14. Goldhaber SZ, Grodstein F, Stampfer MJ, Manson JE, Colditz GA, et al. (1997) A prospective study of risk factors for pulmonary embolism in women. JAMA 277: 642-645.

15. Heit JA, O'Fallon WM, Petterson TM, Lohse CM, Silverstein MD, et al. (2002) Relative impact of risk factors for deep vein thrombosis and pulmonary embolism: a population-based study. Arch Intern Med 162: 1245-1248.

16. Agnelli G (2004) Prevention of venous thromboembolism in surgical patients Circulation 110: IV4-12.

17. Geerts WH, Pineo GF, Heit JA, Bergqvist D, Lassen MR, et al. (2004) Prevention of venous thromboembolism: the Seventh ACCP Conference on Antithrombotic and Thrombolytic Therapy. Chest 126: 338S-400S.

18. Bulger CM, Jacobs C, Patel NH (2004) Epidemiology of acute deep vein thrombosis. Tech VascInterv Radiol 7: 50-54.

19. vanHylckama Vlieg A, Helmerhorst FM, Vandenbroucke JP, Doggen CJ, Rosendaal FR (2009) The venous thrombotic risk of oral contraceptives, effects of oestrogen dose and progestogen type: results of the MEGA case-control study. BMJ 339: b2921.

20. Lidegaard Ø, Løkkegaard E, Svendsen AL, Agger C (2009) Hormona contraception and risk of venous thromboembolism: national follow-up study. BMJ 339: b2890.

21. Hannaford PC (2011) Epidemiology of the contraceptive pill and venous thromboembolism. Thromb Res 127 Suppl 3: S30-34.

22. vanHylckamaVlieg A, Middeldorp S (2011) Hormone therapies and venous thromboembolism: where are we now? J Thromb Haemost 9: 257-266.

23. Kemmeren JM, Algra A, Grobbee DE (2001) Third generation oral contraceptives and risk of venous thrombosis: meta-analysis. BMJ 323: 131-134.

24. Parkin L, Sharples K, Hernandez RK, Jick SS (2011) Risk of venous thromboembolism in users of oral contraceptives containing drospirenone 
Citation: Chalal N, Demmouche A (2014) The Risk of Venous Thromboembolism in Algerian Patients. Pharm Anal Acta 5: 292. doi: 10.4172/21532435.1000292

Page 5 of 5

or levonorgestrel: nested case-control study based on UK General Practice Research Database. BMJ 342: d2139.

25. Jick SS, Hernandez RK (2011) Risk of non-fatal venous thromboembolism in women using oral contraceptives containing drospirenone compared with women using oral contraceptives containing levonorgestrel: case-control study using United States claims data. BMJ; 340: d2151.

26. Kluft C, Lansink M (1997) Effect of oral contraceptives on haemostasis variables. Thromb Haemost 78: 315-326.

27. Rosing J, Middeldorp S, Curvers J, Christella M, Thomassen LG, et al. (1999) Low-dose oral contraceptives and acquired resistance to activated protein C: a randomised cross-over study. Lancet 354: 2036-2040.

28. Middeldorp S, Meijers JC, van den Ende AE, van Enk A, Bouma BN, et al. (2000) Effects on coagulation of levonorgestrel- and desogestrel-containing low dose oral contraceptives: a cross-over study. Thromb Haemost 84: 4-8.

29. Tans G, Curvers J, Middeldorp S, Thomassen MC, Meijers JC, et al. (2000) A randomized cross-over study on the effects of levonorgestrel- and desogestrelcontaining oral contraceptives on the anticoagulant pathways. Thromb Haemost 84: 15-21.

30. Alhenc-Gelas M, Plu-Bureau G, Guillonneau S, Kirzin JM, Aiach M, et al (2004) Impact of progestagens on activated protein C (APC) resistance among users of oral contraceptives. J Thromb Haemost 2: 1594-1600.

31. van Vliet HA, Bertina RM, Dahm AE, Rosendaal FR, Rosing J, et al. (2008) Different effects of oral contraceptives containing different progestogens on protein $S$ and tissue factor pathway inhibitor. J Thromb Haemost 6: 346-351.

32. Odlind V, Milsom I, Persson I, Victor A (2002) Can changes in sex hormone binding globulin predict the risk of venous thromboembolism with combined oral contraceptive pills? Acta Obstet Gynecol Scand 81: 482-490.

33. Wiegratz I, Kutschera E, Lee JH, Moore C, Mellinger U, et al. (2003) Effect of four different oral contraceptives on various sex hormones and serum-binding globulins. Contraception 67: 25-32.

34. van Vliet HA, Frolich M, Christella M, Thomassen LG, Doggen CJ, et al. (2005)
Association between sex hormone-binding globulin levels and activated protein $\mathrm{C}$ resistance in explaining the risk of thrombosis in users of oral contraceptives containing different progestogens. Hum Reprod 20: 563-568.

35. Rad M, Kluft C, Ménard J, Burggraaf J, de Kam ML, et al. (2006) Comparative effects of a contraceptive vaginal ring delivering a nonandrogenic progestin and continuous ethinyl estradiol and a combined oral contraceptive containing levonorgestrel on hemostasis variables. Am J Obstet Gynecol 195: 72-77.

36. vanVliet HA, Rosendaal FR, Rosing J, Helmerhorst FM (2009) Sex hormonebinding globulin: an adequate surrogate marker for venous thromboembolism in women using new hormonal contraceptives. Contraception 79: 328-329.

37. Meissner MH, Chandler WL, Elliott JS (2003) Venous thromboembolism in trauma: a local manifestation of systemic hypercoagulability? J Trauma 54 224-231.

38. Benhamou Y, Marie I, David N, Gbaguidi X, Cailleux N, et al. (2011) [Upper limb deep venous thrombosis]. Rev Med Interne 32: 567-574.

39. Blom JW, Doggen CJ, Osanto S, Rosendaal FR (2005) Old and new risk factors for upper extremity deep venous thrombosis. J Thromb Haemost 3: 2471-2478.

40. Anderson FA Jr, Wheeler HB (1992) Physician practices in the management of venous thromboembolism: a community-wide survey. J Vasc Surg 16: 707-714.

41. Hankey GJ, Eikelboom JW (1999) Homocysteine and vascular disease. Lancet 354: 407-413

42. Prandoni P, Lensing AW, CogoA, Cuppini S, Villalta S, et al. (1996) The longterm clinical course of acute deep venous thrombosis. Ann Intern Med 125: 1-7.

43. Schulman S, Granqvist S, Holmström M, Carlsson A, Lindmarker $P$, et al (1997) The duration of oral anticoagulant therapy after a second episode of venous thromboembolism. The Duration of Anticoagulation Trial Study Group. N Engl J Med 336: 393-398.

44. Hansson PO, Sörbo J, Eriksson H (2000) Recurrent venous thromboembolism after deep vein thrombosis: incidence and risk factors. Arch Intern Med 160: 769-774. 